Pre-print: Cambridge Open Engage, December 2021

Jo Lindsay Walton

University of Sussex

j.c.walton@sussex.ac.uk

\title{
Bitcoin and Stone Money: Anglophone Use of Yapese Economic Cultures 1910-2020
}

\begin{abstract}
Recently parallels have been drawn between Bitcoin and Yapese stone money. This article focuses on Fitzpatrick and McKeon's 2020 exploration of similarities and differences. The analogy between Bitcoin and Yapese stone money is based on proposed commonalities that are inaccurate, ill-defined, and/or trivial. However, this does not signal a need to refine the comparison, but rather a need to reconsider the rationale for attempting it in the first place. Recent attempts to redescribe Yapese stone money using the vocabulary and concepts from the field of cryptocurrency participate in a longer textual history, whereby Anglophone writers have misrepresented Yap for pedagogic or polemic convenience. Examples include works by William Furness III, John Maynard Keynes, Milton Friedman, and influential macroeconomics textbooks, such as N. Gregory Mankiw's Macroeconomics. This history features frequent colonialist troping of Yap and the erasure of histories of colonial violence and power. More caution should be taken in the study and pedagogic use of Yapese economic cultures, especially greater efforts to center Yapese voices, to acknowledge colonial contexts, and to reflect positionality and uncertainty.
\end{abstract}

\section{Introduction $^{1}$}

Recently parallels have been drawn between Bitcoin and Yapese stone money. "Bitcoins are sometimes called virtual cash," write Yuri Takhteyev and Mariana Mota Prado. "But a better analogy is to Rai stones, a currency historically used in Yap" (Takhteyev and Prado

\footnotetext{
${ }^{1}$ Pre-print, not for citation.
} 
2014). Saifedean Ammous claims, "Of all the historical forms of money I have come across, the one that most resembles the operation of Bitcoin is the ancient system based on Rai stones on Yap Island" (Ammous 2018). "[T]he Yapese use a very simple but effective form of what we would now call a distributed ledger," suggests Nick Furneaux. "Amazingly, blockchain-based cryptocurrencies work in almost exactly the same way" (Furneaux 2018). This article demonstrates that these analogies should be rejected, and argues that the rationale for making them in the first place seriously reconsidered.

Bitcoin is a proof-of-work, distributed ledger cryptocurrency, launched in 2009 by an anonymous person or collective under the moniker Satoshi Nakamoto. The Bitcoin blockchain is a complete list of transactions since the currency was created. Network members are anonymous by default, identified on the blockchain by their wallet IDs. ${ }^{2}$ This blockchain is stored in multiple copies spread across all members of the network (hence 'distributed ledger'). A subset of users, called 'miners,' keep the blockchain updated. They do this by compiling transactions that have not yet been added to the blockchain, and broadcasting the new blocks throughout the network. They are incentivised with freshly minted Bitcoin, awarded to the first miners to correctly guess computationally intensive mathematical puzzles associated with new blocks (hence 'proof-of-work'). These puzzles are asymmetric in that solutions are time-consuming and expensive to generate, but can be verified quickly and cheaply. This process is also how the Bitcoin supply grows. Bitcoin is often described as a 'decentralised' cryptocurrency, because it is relatively opaque to state scrutiny.

Crystalline limestone disks, called rai or fei, ${ }^{3}$ are a form of money used on the South Pacific island of Yap (Waqab), today part of Micronesia. ${ }^{4}$ Rai stones vary in size from a few inches to about twelve feet. They were cut in quarries on other islands, principally Palau, over 450 kilometers southwest on a straight line, then transported to Yap via canoes and rafts, and later Western ships. These voyages were lengthy and dangerous, and

\footnotetext{
${ }^{2}$ Users can de-anonymise themselves by demonstrating that they hold the private key corresponding to the public key associated with a particular wallet.

${ }^{3}$ I conform to the most common English transliteration (rai), although raay is also used.

4 Unless otherwise noted, in this article I will use 'Yap' to refer to Yap Main Islands (four very close islands, often also called 'Yap proper'), and not to Yap State (the state within the Federated States of Micronesia, including Yap Main Islands as well as Yap Neighboring Islands such as Ulithi, Fais and Woleai).
} 
seafarers would sometimes lose their lives. Radiocarbon dating currently suggests a very tentative date of around 1400 for the origin of some kind of rai system (Glumac and Fitzpatrick 2020). Colonial powers ended the production of stones in the early 20th century, and later destroyed large part of the stone stock. Stones remain in use, although their precise role within Yapese economic cultures has transformed over time, so caution should be used in ascribing continuity over this period. ${ }^{5}$ Their economic significance in the early 2020s appears to be far less than previously. Contrary to what is implied by many economics textbooks, there is no evidence that rai stones were ever the sole money used on the island. Yapese economic history involves a number of other moneys and media, including shell money, cloth money, and the national currencies of colonial powers.

To date, the most expansive and thoughtful comparison of Bitcoin and stone money is Scott M. Fitzpatrick and Stephen McKeon's 'Banking on Stone Money: Ancient Antecedents to Bitcoin' (2020). The authors present the manufacture and use of stone money as "an analog for cryptocurrencies and blockchains that ensure transparency, integrity, efficiency, and security," while also noting "key differences between Bitcoin and rai, some of which led to the downfall of the rai monetary system" (Fitzpatrick and McKeon 2020, 10). They highlight circumstantial evidence that stone money may have inspired Bitcoin, and contend that comparative analysis may deepen our appreciation of cryptocurrency's properties and potentials.

In the early sections of the article, I question the rationale for pursuing such an analogy in the first place. I do this by contextualizing it within a longer history of Anglophone political economy featuring Yap. ${ }^{6}$ This reveals how stone money has been repeatedly reconstructed to suit individual authors' polemical and pedagogic purposes. In the penultimate section of the article, I examine Fitzpatrick and McKeon's comparison on its own merits. Although the analogy is intriguing, no specific point holds up to scrutiny. Each is either ill-defined, unconvincing, and/or trivial.

\footnotetext{
${ }^{5}$ See e.g. Hezel 1995 p. 179; Egan 1998 pp. 80-84 and passim. One example looms large: Captain David Dean O'Keefe, a settler colonist and merchant who involved himself heavily in Yapese commerce and politics in the latter part of the nineteenth century, catalysed major transformations in stone money use.

${ }_{6}$ In this regard, I don't lay claim to any authoritative knowledge of Yapese economic cultures; my methodology is broadly literary-critical, reflecting my primary background and training. By examining a selection of significant texts, it is possible to identify lacunae, interpolations, and contradictions both within individual texts and across the corpus as a whole.
} 
This leads me to urge greater caution in the study and pedagogic use of Yapese economic cultures. Until the pattern of opportunistic conjecture is acknowledged and redressed, I suggest, efforts at linking Bitcoin and stone money are likely to merely perpetuate it. Broadly in line with a diverse economies perspective (Gibson-Graham 2007), I do also wish to affirm the value of research into more-than-capitalist economic forms, and their complex entanglements with capitalism past and present, even when such research means operating tentatively, far from one's comfort zone. In this spirit, my final section is more speculative. It mobilizes what I have so far learned to pose some questions about Yapese economic cultures, and more generally about the role of storytelling in topologies of wealth.

\section{Island of Stone Money}

In 1910 the American ethnographer William Henry Furness III published Island of Stone Money, based largely on his two-month stay on Yap seven years previously. At this time there was a significant body of writing about Yap in German, but little in English. ${ }^{7}$ Furness's book included chapters on religion, dance and song, the construction of houses, and other topics. In the chapter 'Money and Currency,' Furness described stone money, and mentioned the "small change" (Furness 1910, 102) of shell money and cloth money. He also suggested in passing that money was not strictly necessary on Yap, given the abundance of natural resources.

Furness also spun a story that was to live vividly in the imagination of Western political economy for more than a century. It concerned the circulation of stone money:

After concluding a bargain which involves the price of a fei too large to be conveniently moved, its new owner is quite content to accept the bare acknowledgment of ownership and without so much as a mark to indicate the exchange, the coin remains undisturbed on the former owner's premises.

$[\ldots]$

\footnotetext{
${ }^{7}$ I have not been able to find information on whether there was yet significant Japanese writing.
} 
Many years ago an ancestor of this family, on an expedition after fei, secured this remarkably large and exceedingly valuable stone, which was placed on a raft to be towed homeward. A violent storm arose and the party, to save their lives, were obliged to cut the raft adrift, and the stone sank out of sight. When they reached home, they all testified that the fei was of magnificent proportions and of extraordinary quality, and that it was lost through no fault of the owner. Thereupon it was universally conceded in their simple faith that the mere accident of its loss overboard was too trifling to mention, and that a few hundred feet of water off shore ought not to affect its marketable value, since it was all chipped out in proper form. The purchasing power of that stone remains, therefore, as valid as if it were leaning visibly against the side of the owner's house, and represents wealth as potentially as the hoarded inactive gold of a miser of the middle ages, or as our silver dollars stacked in the treasury at Washington, which we never see nor touch, but trade with on the strength of a printed certificate that they are there.

(pp. 96-99)

Furness supplemented this with another episode, relating how German colonial authorities collected fines by marking stones with black paint, rather than physically moving them. The tone is cheerful, though the subject is the coercion of an indigenous population to labor to construct infrastructure to facilitate their surveillance and control.

A few years after Furness published Island of Stone Money, Bronisław Malinowski's Argonauts of the South Pacific (1922) and Marcel Mauss's The Gift (1925) would transform economic anthropology by placing gift-giving at its heart. Gifts now seem a striking omission in Furness's account. In particular Furness does not mention Yapese mitmit ceremonial exchange, nor the sawei system of exchange with islands to the east. He does briefly refer to rai stones as funeral gifts, ${ }^{8}$ and as gifts related to "the seizure of a young girl to fill the office of mispil" (Furness 1910, 49). ${ }^{9}$

\footnotetext{
${ }^{8}$ See Born (1903a) and Egan (1998). On returned gifts, see Egan (1998), p. 262.

${ }^{9}$ I haven't been able to find any very convincing sources about this; cf. Senfft 1903 p. 11; Born 1903b pp. 5 and 9; Müller 1917 p. 391; Hunt et al. 1949 p. 85; Schneider 1953 p. 218n; Beauclair 1963 p. 159; Lingenfelter 1972 pp. 114, 156.
} 


\section{Anglophone Ethnographies and Histories of Yap}

Over the 20th century, historical, ethnographic, sociological, numismatic, and archaeological texts gradually painted a richer picture of Yapese economic cultures (Lessa 1950; Moore 1952; Beauclair 1963; Lingenfelter 1972; Gillilland 1975; Labby 1976; Hage and Harary 2010; Hunter-Anderson and Zan 1996; Egan 1998; Fitzpatrick 2003; Descantes 2005). Insofar as the stones were money, they were money with manifold functions, not reducible to medium of exchange, unit of account, and store of value. They circulated not merely to coordinate production and consumption, but to cultivate and transform qualitative relationships within and between communities. For example, W. Robert Moore connected stone money with gift exchange and levelling mechanisms (Moore 1952, 805-30). Inez de Beauclair mentioned its use in funerals, adoptions, ransom of an enemy killed in war, compensation for injury, the inauguration of communal houses, as a commitment to future land transfer, for expert canoe building, as well as for purchase of foodstuff (Beauclair 1963, 158-59).

David Graeber suggests the term "social currencies" for this broad category of moneys, used principally "to create, maintain, and otherwise reorganize relations between people" (Graeber 2011, 130). Graeber's approach draws on Philippe Rospabé's parallel between wergeld and bridewealth, and Rospabé's observation that these valuables circulate not so much to clear debts, as to symbolically affirm non-equivalence (Rospabé 1995). Social currencies structure patterns of indebtedness that are typically permanent, albeit plastic, parts of the participants' life stories.

I don't of course imply that the texts listed above are unproblematic, nor without their many contradictions and controversies. However, their problems pale in comparison with a second tradition of Anglophone writing on Yapese economic cultures. This second tradition is concentrated in brief remarks by the economists John Maynard Keynes and Milton Friedman, and dozens of editions of introductory economics textbooks. It is typically uninformed by any appreciation of gift exchange, reciprocity, or social currencies. It has also adamantly ignored the plural, connected, and reflexive economic cultures to which Yapese stone money belongs. 


\title{
Anglophone Economics: John Maynard Keynes
}

In 1915, the Royal Economy Society's Economic Journal republished three pages from The Island of Stone Money. This included Furness's accounts of the stone lost overboard, and the desecration of stones by German occupiers to extract labor for roadworks. It omitted the other moneys that Furness documented. John Maynard Keynes, as the journal's editor, is plausibly who selected the excerpt. Keynes, although he got mixed up about the name, was apparently once more thinking of Yap in the following footnote in A Treatise on Money (1930).

\begin{abstract}
The earliest example of 'ear-marking' is in the case of the stone money of Rossel Island, which, being too heavy to move without difficulty, could be conveniently dealt with in no other way. One of the largest and most valuable of these stones lay at the bottom of the sea, the boat which was importing it having capsized. But there being no doubt that the stone was there, these civilized islands saw no objection to including it as part of their stock of currency - its lawful owner at any time being, in fact, thereby established as the richest man in the island - or to changing its ownership by 'ear-marking'.
\end{abstract}

(Keynes 1930, Vol II, 292n).

The context is telling. Keynes was bringing up Yap in a rather playful preamble about social and psychological attitudes toward gold, before getting down to the serious business of scrutinizing the case for an international gold standard. Keynes wanted to argue that gold has no special characteristics as a commodity that would uniquely qualify it as a stable currency basis. Moreover, since the war, gold had remained concentrated in central bank reserves. Circulating neatly around central banks, rather than looping on wide rambling circuits through a variety of different social contexts and agencies, gold had grown more 'abstract.' That is, Keynes surmised, the agency of gold had grown relatively subordinate to state bureaucratic control. He even wondered if the gold standard might be ceremonially preserved in an emergent essentially fiat system. 
For Keynes, Furness's story thus held two attractions. First, Keynes could use stone money to reinforce the idea that there was nothing intrinsically special about gold as a standard of value. Second, the sunken stone might be claimed as a case of hybrid money between representative money and pure fiat money. In both the case of gold centralised during the war, and that of the stone, the 'backing' commodity of the monetary system is 'sunken' on the sea bed, in the central bank vaults - and unavailable for general circulation.

Keynes's broader account has many merits, but his use of Yap established a dismaying pattern: limited and slapdash use of sources ("Rossel Island"), exoticizing or condescending admiration ("these civilized islands"), unexplained additions (the lawful owner of the sunken rai being "the richest man on the island") and alterations (the stone "changing its ownership by ear-marking," rather than remaining in the possession of one family as in Furness's account), and sneaking in concepts which mystify rather than illuminate ("ear-marking" in contrast to Furness's "without so much as a mark to indicate the exchange"). Perhaps most significantly, Keynes quietly filtered out the lesson Furness drew that "labour is the true medium of exchange and true measure of value" (q.v.), and Furness's curious post-scarcity claim, but without registering any dissent. Here, as in many later texts, the repurposing of Yap needed to be discreet, lest its lose its allure as a pristine exemplar of universal laws. It would not have suited Keynes' rhetorical purposes for Yap to be encountered as an immanent presence within history, textually mediated, and subject to interpretation and dispute. Yap, it seems, was only worth arguing with, not about.

\section{Anglophone Economics: Textbooks}

Similar patterns appear in multiple editions of textbooks from the 1940s till today, including Dodd's Introductory Economics; Amacher's Principles of Economics; Mankiw's Macroeconomics; Baumol and Blinder's Economics: Principles and Policies; Ruffin and Gregory's Principles of Macroeconomics; Miles and Scott's Macroeconomics: Understanding the Wealth of Nations; and Williamson's Macroeconomics. Yap is often boxed off in a side-bar, implicitly framed as somewhat ornamental optional reading, to 
embroider necessarily dry material. Presentations vary in small ways, often easily missed. But these variations reflect at least two things.

First, willingness to filter and alter Yapese history for the sake of convenience. For example, whereas Keynes used stone money to show fiat moneys in a good light, Amacher's second edition Principles of Economics mobilizes it in a diametrically opposite way, on behalf of commodity or metallic standard moneys. For Amacher's purposes, then, stone has useful connotations of stability and permanence. But these could be mitigated by the spectacularly perilous and unpredictable production process. So Amacher simply does not mention that stones were quarried on Palau, and even generalises Furness's anecdote to many, or perhaps all, sunken stones: "even stones that are now under the sea maintain their value, and their ownership, though not location, can be changed" (Amacher 1983, 63). At the same time, Amacher also implies that stone money is no longer used.

Second, these variations reflect incoherence in the textbooks' own understandings of money. The textbook accounts of Yap are almost always situated near an introduction to money's functions and origins, ${ }^{10}$ grounded in the commodity theory of money: money is presented as a means of exchange, a unit of account, and a store of value ${ }^{11}$; its origin is located as a conveniently inevitable solution to the inconveniences of barter, especially the inconvenience of the "double coincidence [of wants]" (Jevons 1875, 5). Money is purported to emerge to avoid the situation where "if Farmer Jones grows corn and has a craving for peanuts, he has to find a peanut farmer, say, Farmer Smith, with a taste for corn" (Baumol, Blinder, and Solow 2020, 237). ${ }^{12}$ Throughout the history of modern economics, this has been the dominant entry-level theory about money, even though, as the anthropologist Caroline Humphrey puts it, "Why should anthropologists be interested in logical deductions from an imagined state? No example of a barter economy, pure and

\footnotetext{
${ }^{10}$ That is, what the textbooks refer to simply as 'money' and which is tacitly state-capitalist money, usually fiat. The Dollar, Sterling, the Yen, the Renminbi, the Euro, et al. are treated as distinctively and superlatively characteristic of 'money' in a way that the stones of Yap are not.

${ }^{11}$ And sometimes a standard of deferred payment.

12 Caroline Humphrey also points out that barter should also be at least an "open-ended, potentially innovative, negotiable, transaction, in which need not only answers need but can also create a new demand: 'If you don't want these potatoes, perhaps you would like this pair of scissors?'" (Humphrey 1985, $50)$.
} 
simple, has ever been described, let alone the emergence from it of money; all available ethnography suggests that there never has been such a thing," (Humphrey 1985, 49). ${ }^{13}$

In fact, economic anthropology leaves little doubt that societies that are 'moneyless' in the textbook sense use complex localised systems of reciprocity, involving gift relations and social currencies. However, for mainstream economics, especially the broadly neoclassical tradition, the discredited commodity theory of money retains significant allure. This is largely because the theory downplays the dual role of money as an instrument of power and a reflection of non-monetary power, instead emphasizing order emerging from the self-interested action of many atomic individuals. Positioning money as a commodity among others (distinguished only by its minimal intrinsic value) also dovetails well with the notion that money is merely a neutral or largely neutral veil over the real economy.

Yapese stone money is a spectacularly poor fit for this theory. Nevertheless textbook authors appeal to it again and again, filtering and manipulating it in various ways in creative efforts to prolong their untenable theory. For example, William J. Baumol and Alan S. Blinder's third edition Economics: Principles and Policy focuses on the idea that money works efficiently if it is uniform, divisible, durable, and storable. Using gold and silver as a starting point, on the implausible assumption that these have "high value in nonmonetary uses," the authors propose a genealogy in which these four qualities inexorably increase (Baumol and Blinder 1985, 224). ${ }^{14}$ The information they include about Yap is an abridgement of Art Pine's 1984 Wall Street Journal article (Pine 1984); their brief framing is enough to indicate how they want to use Yap: "Primitive forms of money still exist in some remote places, as this extract from a recent newspaper article shows" (224). For Baumol and Blinder, Yap is stuck in an especially bad version of their first phase, burdened with money so heterogenous, indivisible, and difficult to store that it ought to be obsolete. The abridgement itself is also telling. They omit Pine's reference to lower-value stones, produced with the assistance of the man Pine calls "David Dean O'Keffe" [O'Keefe], which would throw doubt on Baumol and Blinder's presentation of

\footnotetext{
${ }^{13}$ Humphrey goes on to explore the conditions under which societies may become dominated by barter, including intriguing uses of money that are better classed as bartering than paying.

${ }^{14}$ Baumol and Blinder's account also does not address the fact that coins can and often are fiat currency; face value and bullion value are conflated for convenience, and debasement and seigniorage are not mentioned.
} 
the stones as a kind of substitute bullion. Similarly, they stress indivisibility, and even imply the stones may not be that durable — "the stones are worthless when broken" (p. 253) - yet leave out Pine's next point, which echoes Furness and Keynes:

Rather than risk a broken stone - or back - Yapese tend to leave the larger stones where they are and make a mental accounting that the ownership has been transferred - much as gold bars used in international transactions change hands without leaving the vault of the New York Federal Reserve Bank.

(Pine 1984)

David Miles and Andrew Scott, in Macroeconomics: Understanding the Wealth of Nations (2002), are even more inventive. As with other textbooks, they set out a version of the commodity theory of money, including the suggestion that "it is bizarre to quote prices in terms of a commodity when transactions do not actually involve the exchange of that commodity" (Miles and Scott 2002, 298), bypassing many historical instances, attested at least since Homer's Iliad, where precisely this has been the case. But their most distinctive claim is that Yap employed a paper currency backed by rai stones:

As long as you had a piece of paper that proved you owned a stone (which may be stored miles away and never moved), you had something valuable. [...] So this is one (big!) step removed from pure commodity money. We are talking about a system in which paper claims circulate as money.

(Miles and Scott 2002, 299)

Some textbooks are less flagrantly inventive, while still finessing their presentation of stone money to reflect their authors' preoccupations and priorities. Stephen D. Williamson's second edition of Macroeconomics compares "Yap stones" with playing card money in 17 th century New France. For Williamson "the commodity backing of the playing card money was uncertain (due to the inability of public officials to keep their promises)," whereas "the existence of the Yap stones was well-known to essentially everyone on the island" (Williamson 2005, 539). Williamson's emphasis on social and 
political institutions underpinning price stability versus inflationary pressure reflects the broadly new monetarist concerns.

The commodity theory of Ruffin and Gregory's sixth edition Principles of Macroeconomics frames money as a productivity-improving information technology. In contrast to Baumol and Blinder's emphasis on indivisibility, Ruffin and Gregory impose a kind of shareholder system on stone money: "[a] particular large stone may be owned by many residents, each of whom has received some part of the stone in exchange for some product or service." This plays into their verdict that "[t]he informational requirements of stone money are too great (each stone has a history) for a complicated world" (Ruffin and Gregory 1997, 201) and that it will presently be superseded by more impersonal, fit-for-purpose money technology. ${ }^{15}$

Mankiw's Macroeconomics (1992) again offers a version of the commodity theory of money, whereby the presumed inconvenience of barter inexorably leads buyers and sellers to converge on some commodity as a conventional medium of exchange. Yapese history is reinvented to show a similar process in action, emphasising unwieldiness rather than the double coincidence of wants. At first, Mankiw imagines, stones were conventionally moved around with each transaction:

The stones were heavy; it took substantial effort for a new owner to take his fei home after completing a bargain. Although the monetary system facilitated exchange, it did so at great cost.

As one might expect, it became common practice for the new owner of the fei not to bother to take physical possession of the stone. Instead, the new owner accepted a claim to the $f e i$ without moving it. In future bargains, he traded this claim for goods that he wanted. Having physical possession of the stone became less important than having legal claim to it.

This practice was put to a test when an extremely valuable stone was lost at sea during a storm. (144-145)

${ }^{15}$ On divisibility, see also Fitzpatrick 2003. 
The source Mankiw cites, Norman Angell's The Story of Money (1929) does not include any early phase in which rai stones physically move with each transaction (Angell 1929). Mankiw seems to have invented it.

This remarkable array of unsubstantiated speculation, mispresented as fact, is compounded by indifference to updating across successive editions. For example, Baumol and Blinder's fourteenth edition alters its account as follows (my emphasis): "Primitive forms of money still exist in some remote places, as this extract from an old newspaper article shows" (Baumol, Blinder, and Solow 2020, 213). Robert H. Frank and Ben Bernanke's first edition Principles of Economics mentions Yap fleetingly, misleadingly describing the rai: "a wide variety of objects have been used as money, ranging from gold and silver coins to shells, beads, feathers, and, on the Island of Yap, large, immovable boulders" (Frank and Bernanke 2001, 668). By the seventh edition, two more editors and some cacao beans have been added, but the "boulders" apparently really are immovable (Frank et al. 2019, 584). Likewise, Mankiw repeats his idea about the progressively dematerializing rai in his tenth edition; tweaks to the phrasing have only become misleading, with "[a]s one might expect" becoming "[e]ventually" (Mankiw 2019). In this edition, however, Mankiw places Yap side-by-side with another intriguing specimen: Bitcoin.

\section{Stone money and Bitcoin: rationales for comparison}

When Yap has appeared in Western economics, the lessons which authors draw often reflect their position in intellectual and political disputes which are not principally rooted in Yapese history or economics. This marginalization is sometimes even proposed as a kind of advantage. By constructing Yap as 'exotic' and yet supposedly comprehended within their analysis, authors intimate the timeless and universal quality of their thought. Felix Martin's Money: The Unauthorised Biography (2014) provides an excellent illustration. Milton Friedman quotes Furness's Island of Stone Money at length in Money Mischief (1992). This impresses Martin, who describes Furness's book as “obscure," and the fact that Keynes and Friedman both referred to it as "a strange coincidence," despite the ample representation of Yap in textbooks, and the rather obvious fact that Friedman read Keynes (Martin 2014, 13). ${ }^{16}$

${ }^{16}$ Friedman might for example have come across the 1915 Economic Journal, or seen Keynes's 1930
account, or accounts by Dodd, Amacher, or Baumol and Blinder, among other places. Yap appeared in 
Furness pondered the "simple-hearted" people who had "never heard of Adam Smith or Ricardo" (Furness 1910, 92), yet who in his eyes vindicated the labor theory of value; Martin paralleled this a century later by framing the Yapese economy as "simple" and "rudimentary," and marvelling that two "giant[s] of economics" as different as Keynes and Friedman can come to the same conclusions about it (Martin 2014, 13). But outside of Martin's selective framing, they didn't. Keynes focused on the first of Furness's anecdotes, and Friedman on the second, in line with their divergent instincts about the tractability of material wealth to policy interventions. Keynes, the sea bed; Friedman, the black paint. ${ }^{17}$

I now focus on 'Banking on Stone Money: Ancient Antecedents to Bitcoin' by Fitzpatrick and McKeon (2020); Fitzpatrick has published extensively on Yapese stone money and is an authority on its carbon dating; McKeon brings his expertise in cryptocurrency. I propose that the larger context of opportunistic use of Yapese economic cultures, as already briefly sketched, gives us good reason to be extremely cautious about any attempted analogy between stone money and Bitcoin. In the next section, Fitzpatrick and McKeon's analogy will be nonetheless considered on its own merits.

more popular press too, for example, National Geographic in 1921,1942, 1946, and relatively extensively in 1952. Yap also appeared with some frequency in numismatic publications such as The Numismatist, Coin World, and Numismatic News, and The Centinel. Rai stones exist outside Micronesia in museums; the Smithsonian collected a smaller stone in 1897 and a larger one in 1962. There was a novel about O'Keefe's time in Yap (Klingman and Green 1950), adapted into a movie starring Burt Lancaster (Haskin 1954). Friedman's excerpt begins and ends exactly where the Economic Journal excerpt does, and the Economic Journal introduces a minor modification to the punctuation which also appears in Friedman's excerpt. Friedman does quote the page numbers of Furness's Island of Stone Money, rather than the Economic Journal.

${ }^{17}$ That is, if - and it is a big if - one were determined to read Yapese stone money as a parable about commodity money and representative or fiat money, Furness's two stories actually offers two sharply different angles. The sunken rai features in a story about successfully transitioning from commodity money to representative money, in at least one instance. Through a policy decision, aggregate demand is increased compared to what it would otherwise be. By contrast, the black crosses (in Furness's version) feature in a narrative about being violently prevented from making such a transition. This narrative is about an obdurate materiality that places hard limits on the generation of value through policy alone. Yapese communities are unable to deem the marking of rai by the occupying colonial power "too trifling to mention" (Furness, q.v.). Were the occupiers to return and destroy a stone, it is implied, it would be unlike simply to circulate, "as valid as if it were leaning visibly against the side of the owner's house" (Furness, q.v.). The evolutions and relations of Keynes and Friedman's macroeconomic theories are of course complicated. Nevertheless, very roughly speaking, given their broad instincts around how monetary and fiscal policy impact the economy, one might well expect Friedman the monetarist to emphasize the story about the limitations of policy decisions, and Keynes, already on his way to developing his influential account of government deficit spending to boost employment, to emphasize the story about the power of such decisions. 
Fitzpatrick and McKeon's analysis, while more measured than many so far considered, nonetheless perpetuates many of the same tropes. In particular, Bitcoin and stone money are described as having been invented "to solve similar societal problems" (Fitzpatrick and McKeon 2020, 19). This rationale for comparison signals a concern for universal economic laws underpinning diverse socio-political expressions. In this respect it resonates with earlier constructions of Yap as an idyllic and untainted setting for the observation of such laws. It likewise resonates with techno-utopian constructions of Bitcoin as peculiarly disembedded from social and political life, as Nigel Dodd describes:

Insofar as Bitcoin has been successful qua money, it is because of the community that has grown up around it. Ironically, however, this community is sustained by the commonly held belief that Bitcoin has replaced social relations - the trust on which all forms of money depend - with machine code. This belief is a fiction. Bitcoin has thrived despite, not because of, its reliance upon machines.

(Dodd 2018)

Another rationale the authors offer for their research is that the rai "may have been a progenitor that inspired Bitcoin" (Fitzpatrick and McKeon 2020, 7). Here they acknowledge that evidence is circumstantial. However, perhaps a better question is whether it is even in doubt. As already sketched, stone money is a ubiquitous presence not only in the work of "numismatists and other scholars whose interests lie in the history of money" (Fitzpatrick and McKeon, 9), but also in introductory economic textbooks. On the whole it appears unlikely that Nakamoto would not have come across stone money. But it is also unlikely that Nakamoto never came across anything else. That is, aspects of Bitcoin have precedents in earlier computer science projects such as Hashcash, Bit Gold, DigiCash, Flooz e-currency, and Hal Finney's Reusable Proof of Work. Wei Dai's b-money proposal integrated a distributed ledger based on cryptographic hashes and public key cryptography, proof of work to generate new currency, and currency incentives for mining. ${ }^{18}$ Culturally, there are partial precedents in speculative fiction, such as the crypto-anarchist digital currency in Neal Stephenson's 'Great Simolean Caper' (Stephenson 1995). Stone money

18 There is some evidence to suggest that the latter, despite its very close parallels, may not have been a direct influence. 
would also have been a potential influence on many of these potential influences. It would be very odd if stone money were somehow not be part of Bitcoin's rich formative matrix. But there is no evidence of the descent of specific conceptual attributes, not available elsewhere, from stone money to Bitcoin.

Given the contradictory accounts already sketched, we must also ask: which version of stone money is supposed to have been Bitcoin's progenitor? The opportunistic fantasies of the textbooks, from Mankiw's entropic circulation to Miles and Scott's stone-backed paper currency? The Smithsonian rai stone curatorial notes, which implies that pigs were the Yapese unit of account prior to the dollar? ${ }^{19}$ The Burt Lancaster film, in which a wise and remorseful Captain O'Keefe orders the rai stones he has quarried be dynamited? ${ }^{20}$ Unsurprisingly, the answer seems to be no existing version, but rather yet another new version, customized to Bitcoin's polemic specifications. Bitcoin's critics have pointed to the volatility of its value, and questioned whether it can be classified as 'real' money. The rai is recruited as a tacit rebuke to such critics. ${ }^{21}$

Thus, even there were interesting questions around stone money and Bitcoin as potentially homologous "solutions" to common "problems," and/or stone money as a potential "progenitor" of Bitcoin (which is doubtful), those questions should not obscure a question of equal or greater significance. How would such an origin story, if it could be made credible, alter Bitcoin's reputation and overall cultural profile? This reveals a more convincing, albeit unacknowledged, motive for Fitzpatrick and McKeon's analogy: that it hopes to annex the obduracy of stone on behalf of the notoriously flighty Bitcoin. Here the longer history I have sketched is again helpful. Within economics, the Anglophone presentation of Yapese stone money has typically involved opportunistic claims about the nature of money, and often specifically been invoked in relation to evolutionary or teleological accounts of money. Bluntly put, stone money has been opportunistically used

\footnotetext{
${ }^{19}$ See Smithsonian, 2015.

20 See Haskin, 1954.

21 Fitzpatrick and McKeon do situate rai money within other exchange media, e.g. shells and cloth, but curiously insist that "in none of these or other cases in the Pacific did the exchange of shells or other resources evolve into what would strictly be defined as a currency." Here the choice of the 'strict' definition of money seems to be reverse-engineered from the point they wish to make: Bitcoin, rai, and dollars are real money; all other moneys described by their users as money, and described by a wealth of economic and anthropological literature of money, falls short.
} 
to illustrate supposed transitions from inferior to superior money forms. The article is in essence a form of cryptocurrency advocacy, rooted in the longevity of the rai, and the suggestion that factors influencing its decline are avoidable in the case of cryptocurrency.

\section{Analogies between Bitcoin and stone money considered}

Textbook authors, eager to illustrate evolution from commodity money to fiat money, have downplayed the role of positionality in establishing rai ownership. Fitzpatrick and McKeon continue this tradition:

[...] what is extraordinary is that once a rai was brought to Yap and ownership established, it would then be placed in a specific location, such as the front of a house or domicile or along dancing grounds, and remain there in perpetuity $[\ldots]$

(Fitzpatrick and McKeon 2020, 13)

This is at best misleading, and the broader literature is filled with examples of some rai stones being moved; for example, this extract from Gillilland:

Though the stones might have been placed outside the men's house, they did not necessarily remain there as a "decorative bank." [...] Rai left the failu as payment for fishing equipment, canoes, for pigs or for a feast. Even festivals and dances, which constituted a great part of the Yapese life, called for the exchange of rai. [...]

(Gillilland 1975, 11)

Overstating the immobility of the stones, Fitzpatrick and McKeon can then marvel that "a shared ledger was used to track ownership of rai centuries before computers were invented" (8). This raises the question of whether Yapese oral tradition can be justly described as a 'ledger.' Even given a generous definition that does not imply technological cognitive prosthesis (such as a book or a spreadsheet), but rather data storage practices principally neurologically instantiated, the oral traditions of Yap remain a rather awkward 
match. To the extent that the lineage of every stone can be traced back through every date-stamped transaction to its original quarrying, this aspect of the comparison would be sound; but to the extent that such lineages are subject to narrative salience, prioritising current location and ownership, recent or highly significant transactions, original provenance, broad patterns of circulation, then it is less sound. The tremendous mnemonic capabilities of oral cultures should not be underestimated, and often far exceed what observers from writing-using cultures initially imagine is possible. However, without further evidence it is not credible that any oral culture preserves transactional histories at the scale and level of detail implied by the authors' blockchain analogy.

Redundancy is a second key aspect of this analogy. The word shared in the term shared ledger may imply — and must imply, if it is to parallel Bitcoin — essentially the same data set, repeated again and again, with only minor and evanescent variations, e.g. because of unsynced local copy, or because of corrupt data that can be corrected against the blockchain. In this respect, oral tradition is once more a spectacularly poor match for Bitcoin. While Yap may possess a relatively "narrow geographic community" (9), it is nevertheless about a hundred square kilometers in extent, with a population in the early 19 th century of around 28,000 to 34,000 , falling to below 3,000 mid-20th century, and at the 2010 census over 11,000 , currently divided into ten municipalities. There are currently around 6,000 stones on the island, and Japanese occupiers counted over 13,000. It is not clear to what period Fitzpatrick and McKeon refer, but even assuming whatever configuration is least challenging, it is not credible that every Yapese 'node' knows the full history of every stone. ${ }^{22}$ Nor is it credible that new transactions spread so rapidly through the network that discrepancies due to latency are negligible. ${ }^{23}$

On any such scale, what is more reasonable to expect is a manifold of overlapping data sets, perhaps mostly reinforcing one another, but with at least potential for lacunae and contradictions. My suspicion is that Fitzpatrick and McKeon might be tempted to concede

\footnotetext{
22 The authors do more-or-less acknowledge these impossibilities, but don't consider them pertinent for a population in the thousands or tens of thousands. "Essentially, there exists a cognitive constraint on the number of rai stone transactions that could be processed through word of mouth, limiting its ability to scale" (16).

${ }^{23}$ The problem with centralized banking is supposedly that "since data are maintained in multiple separate ledgers, the ledgers are not in sync in real time" (10).
} 
such a point as a clarification, except that it is a clarification that causes the analogy to collapse. In particular, consensus in regards rai becomes a strikingly different affair. Far from being automated, consensus may involve deliberation, rivalry, and even legal arbitration (as Gillilland 1975 documents, for example). The circulation of information is liable to be responsive to the structures of communities of place and communities of interest: all else being equal, those who know about a given stone are likely to be those who have some stake in its status.

Not only are these data sets shared in two very different senses, the sharing mechanisms are strikingly different. This is perhaps why block mining and synchronisation are assigned such vague Yapese correlates: "An ancient corollary [sic] to nodes in the Bitcoin network are the villagers of Yap. They confirmed and repeated information about the transaction of rai stones through an oral ledger, preventing double-spending” (Fitzpatrick and McKeon 2020, 15). The question unanswered by Fitzpatrick and McKeon is how, specifically, this information is supposed to be confirmed and repeated. The authors have not specified, but plausibly they refer to mitmit and other occasions of festivity, dance, poetry, ritual dialogue, and gift exchange. If so, it must be emphasized that such occasions have worked both to transform as well as to reaffirm relationships. Moreover, relationships in question regard collective relational identities at the level of estates and villages, rooted in historical incidents and hierarchical divisions of obligation and labor, as well as marriages, births, deaths, adoptions, alliances, feuds, and so on. While this encoding of information may be rich and detailed, it does not map on well to any blockchain-like notion: a long list of current and historic rai proprietorship being verified and updated. As regards traditional dance, for example, Krause (2015) quotes Yap State Senator Ted Rutun, giving a good sense of the style of historical detail encoded:

The information that you need to preserve, you put into the dance. That information may have to do with the relationship between your village and another village. Information that goes into the dancing chant may have to do with a time when disaster struck so that people would know, future generations would know that in such a time a war was waged on the village - the village was attacked. Or a storm hit the village and killed so many 
people. Or something that is more celebrated like the arrival of something good - is it the stone money from Palau, or when they got a necklace [highly valued traditional money] from somewhere? The way they went through obtaining those things would be detailed in the dance. [...] So instead of reading a book, it's an oral history that was about the creation of this nation.

(Krause 2015, 52)

"Transparency is a key feature in both systems" (15). If this observation is to be anything other than trivial, it must be acknowledged that different aspects of the two systems are available to public scrutiny. With respect to Bitcoin, what is made public is a complete history of transactions among anonymized entities. ${ }^{24}$ Bitcoin is conspicuously opaque in other respects, and its capacity to elude state scrutiny is often declared one of its advantages. To anonymously conduct a ransomware attack and accept payment in rai would be difficult. ${ }^{25}$

The authors go even further, suggesting that "Both oral and digital blockchains represent an 'unequivocal source of truth' where anyone within the system (island society or electronic realm) can know and observe the entire transaction history, enabling auditability" (15). Of course, in the case of Bitcoin, only certain types of truths are available in the way described, excluding many that might be highly relevant for auditability. (More pedantically, Bitcoin is also in principle susceptible to unauthorised spending, 51\% attacks, and race attacks. The capacity for Bitcoin to fork also casts doubt on the applicability of as zealous a phrase as "unequivocal source of truth").

In the case of what the authors characterize as an "oral [...] blockchain" (q.v.), it would be absurd to characterise community memory of any kind as unequivocal, however intensively ritually synced it is. Moreover, as Egan (1998) writes:

\footnotetext{
${ }^{24}$ An entity might voluntarily de-anonymize by using their private key to generate a signature proving ownership of an address.

${ }^{25}$ Moreover, contextualizing stone money within the wider flows of wealth might paint a different picture: "Yapese hid their wealth, be it shell valuables, cash, or planted food in order to give themselves control over its disposal. Friends, relatives, and fellow villagers could not make claims to what they did not know existed. Claims were not only a matter of seeking needed support from those able to give it" (Egan 1998, 77-78).
} 
Yapese believed that knowledge had to be fragmented and kept secret to provide bases of power while at the same time curtailing its centralization. Yapese jealously guarded detailed knowledge of histories, of formal political relations and protocols, and of magic and important technical skills. [...] Keeping knowledge secret and segmented prevented the possibility of anyone learning too much and using their accumulated information to press new claims to authority.

(Egan 1998, 75-76)

Fitzpatrick and McKeon also suggest scarcity per se as grounds for the analogy, which can be rejected as trivial since there are no non-scarce moneys; the conditions that sustain the scarcity of e.g. the Euro may be somewhat complex, but the fact of its scarcity is not in doubt. However, the claim about scarcity is really leading toward a more interesting claim, to do with work: "Within fiat monetary systems, central banks manage expansion and contraction of the money supply. In contrast, expansion of the money supply in both rai and Bitcoin is generated solely through contribution of work" (220).

No reason is given for limiting the scope of comparison here to Bitcoin, stone money, and fiat money. It is worth noting that the inclusion of coinage or gold standard money might well make Bitcoin and stone money feel relatively dissimilar: mining limestone and mining gold must have some resemblances. This aside, the chief problem is that the word work has a specialist sense in the context of Bitcoin, especially in the term proof-of-work: work refers to computational resource expended by miners to guess a number (called the golden nonce) that will permit them to append the next block of transactions to the blockchain and claim a bitcoin reward. Work in this sense can only be carried out by owning or leasing technological capital. As Fitzpatrick and McKeon note, it also has significant energy requirements, currently met through a mix of renewable sources and unsustainable fossil fuels. ${ }^{26}$ The strikingly different materialities of work in the case of Bitcoin and rai should not be glossed over, any more than the strikingly different materialities of mining.

\footnotetext{
${ }^{26}$ As Micronesia is among the Pacific Small Island Developing States, exposed to the effects of sea level rise, there is a missed opportunity to remark more holistically on Bitcoin's entanglements with Yap.
} 
Moreover, the notion that "central banks manage expansion and contraction of the money supply," while not strictly untrue, in this context is misleading. The comparison is around money creation, and most national money supplies are enlarged ex nihilo by banks issuing loans (Keynes 1930; Pettifor 2018). The degree to which this is managed by central banks both is a matter of controversy and is variable across time and space (Ingham 2004). Fitzpatrick and McKeon's tacit distinction between the non-work of adding a new loan to an account spreadsheet, versus real work - such as cutting and transporting rai stones, or guessing golden nonces - should be rejected. At the very least, loans must be applied for and approved: the banking system which enables the existence of fiat money is unmistakeably sustained by work in a broad sense.

This analysis has focused on factors that are cognate with earlier misrepresentations of Yapese economic cultures, including an exaggerated picture of Yap as isolated, ahistorical, geographically small, and socially homogenous; the shoehorning of Yapese traditional practices into unsuitable and misleading technical vocabularies; and the omission of histories of colonial violence. Other objections might also be raised. But by maintaining this focus, I hope to avoid dignifying via rebuttal the existing analogies between Bitcoin and stone money. Such analogies not only ask to be rejected. They also invite examination of the underpinning neocolonial presuppositions that led some observers to experience them as salient and plausible in the first place. 


\section{Narrative Currencies}

I want to conclude more speculatively, by considering the role of storytelling. Some individual rai stones are implicated in stories. Are individual bitcoins? It depends what you mean by 'storytelling.' 'Storytelling' may refer to the bare scraps of 'plot' constitutive of ledger transactions; or to historical episodes of the recent past artfully brought to life; or to a longer tradition of folk tales and legends filled with tricksters, heroes, victims, villains, and the like; or to the stories we believe about ourselves, that is, something akin to 'ideology' or our 'social imaginary.' The distinctions as well as the continuities between these storytelling forms are significant.

Though both Bitcoin and rai stones involve storytelling, they do so in ways which distinguishes them rather than draws them together. At the heart of the Bitcoin blockchain is a vast tale of numbers churning into other numbers. The iteration and expansion of this principally numeric narrative is a relatively automated process, and not a particularly suitable arena for the staging and adaptation of cultural values and norms. ${ }^{27}$ By contrast, the reproduction of rai knowledge over time — "with ritual gatherings and social events serving as the verification of ownership" (Fitzpatrick and McKeon 2020, 15) - entails the rehearsal and potential revision of values, histories, norms, personalities, affects, and so on. One of Yap's more storied stones has been, curiously, the focus of non-Yapese storytellers, who have poured it full of values, myths, lessons, and structures of feeling, often negotiating with or contesting previous storytellers. Why has the stone on the sea-bed proved so enduring? Perhaps because the stories it carries are about the origin and legitimacy of capitalist money. That is, they are supranational myths, justifying the hegemony to which these storytellers loosely belong. In this limited sense, the capitalist world system can be said to have been absorbed into the traditional Yapese economy, as well as the reverse. Consider, for example, another story about a lost stone, recorded by the German anthropologist Wilhelm Müller not long after Furness’s visit:

Gāfinněmālắl and Tāmātšốn were two people from the village of Lamar. They went in a canoe to Palau to fetch a rai as a charm for mosquitoes, which did

\footnotetext{
${ }^{27}$ A blockchain money with a prominent role for rich representations of human histories would be perfectly feasible, of course. But Bitcoin is not that.
} 
not exist in Yap before. They planned to send these mosquitoes into enemy villages as aids to war, so that the people, bitten at night, would drowse in the day and might be attacked. On the homeward leg, before they reached Yap, a great storm blew over and swamped the stone. This happened near the village of Malai. Then many mosquitoes descended from the sky and bit the two stone-bringers. They fled, abandoning the fōfốd which carried the stone to drift. Tāmātson hid himself in a pool, sticking only his face out of the water. Gāfinněmālắl wrapped himself in netting, but was still stabbed to death. The stone itself was taken by the currents to Nel, where it can still be found today. Another piece drifted to Ronu. ${ }^{28}$

Why isn't the punchline to this story, 'Yet despite never arriving at its destination the stone circulates to this day?' What kind of story is this, and how does it differ from that related by Furness? One obvious difference is that it names individuals and places. "This happened near the village of Malai": for such a brief tale, this detail may feel unnecessary. Yet were a storyteller to omit it, they would lose the connection to other stories about Malai. Names create the opportunity to conduct dialogue through interconnected narratives. Stories tell stories about stories, and in their palimpsestuous interplay, good and bad, right and wrong, true and false, beautiful and ugly, can be drawn and redrawn. ${ }^{29}$ One therefore wonders if there were named individuals and places in whatever Fatumak told Furness.

Non-Yapese storytellers have consistently rejected such affordances. That is, storytellers such as Furness, Keynes, Mankiw, and Friedman, have elected to treat their source material as history, and a history evacuated of its didactic, mythic, ironic, spiritual, and agonistic contents at that. They begin from the stance that an event has happened, and it falls to them to extract its lesson. In Furness's retelling, the story teaches a labor theory of value. In Keynes's retelling, the story teaches us of the passing of the gold standard, and so on. They do not consider that the episode may already have been formulated as a lesson.

\footnotetext{
${ }^{28}$ My translation (Müller 1918). Fōfốd refers to a kind of Yapese raft.

29 "Another piece drifted to Ronu": does this perhaps have the feel of a later interpolation, very characteristic of oral transmission? A stage also seems to be missing; we never hear of the stone breaking apart. Or perhaps it is a second rai that drifts to Ronu?
} 
What lessons might it have taught, just prior to Furness's retelling? What might Fatumak have said with the story? I can only tentatively guess. On balance, it seems unlikely to be saying that every stone that sinks can still circulate perfectly well, or that the physical stones can be dispensed with altogether, in favor of a ledger of virtual stones. Later Western storytellers would gradually push the tale in that direction. It feels more likely to me that this is a story about an exception, although the nature of that exception has been erased in Furness's recollection.

Indeed, probing the conditions of possibility for a lost rai to circulate might have been precisely the point of the original story. One intriguing possibility is that, in this story, it is simply the size and beauty of the rai that makes its characters behave so unusually. It would then be a story that imagines something so valuable that you cannot help but tell the truth about it, and people cannot help but believe you. Furness's retelling includes the intriguing phrase "lost through no fault of the owner" (97). Another difference is that Gāfĩněmālắl and Tāmātšốn feature in an origin myth. Their story apparently explains where mosquitoes came from. It also seems to be a story about hubris. It reminds me of proverbs I'm familiar with from my own cultures: a taste of your own medicine. Hoisted on your own petard. Are we invited to suspect that in this case, Gāfiněmālắl and Tāmātšốn were at fault for the violent storm which arose, and for the loss of the stone?

It is also worth considering the timing of the story Furness ascribes to Fatumak. Apparently largely through David Dean O'Keefe's interventions during the last decades of the nineteenth century, the total size and the distribution of the stone money stock had dramatically altered, heralding instability and fluidity as villages vied for power and prestige. Meanwhile, the population of Yap was continuing its long decline. Rai production was for perhaps the first time under serious threat from the colonial authorities, after an 1899 order to end quarrying, apparently both as a move against O'Keefe, and an attempt to secure more Yapese labor for roadworks and other projects (Gillilland 1975, 11). The question of whether and how to resist this colonial prohibition may well have been pressing. So might the story about the half-lost rai stone also be a half-lost political allegory? One skeptical of further rai importation as an insurrectionary priority, given its recent sowing of contention among Yapese, enriching upstarts and foreigners? 
Traditionally peril, injury and loss of life would increase the value of the rai. ${ }^{30}$ But here, might the moment of cutting loose the rai raft and surviving the story carry a symbolic significance for Yapese society as a whole?

This is of course all violently conjectural. But if it were roughly this kind of story, it need not have recently sprung into existence. It might rather be a case of an older story revivified by its affordances for engaging with contemporary social anxieties and opportunities. Maybe the sea-bed rai could be considered part of a proto-origin myth. Perhaps for now it was merely a story about a single ghostly rai leaning outside a single house, despite also lying on the sea floor. Yet in time, through slow increments of implicit narrative deliberation, perhaps the story could accrue much greater solidity. Perhaps it could grow to legitimate some aspect of some version of a partly or fully dematerialized rai currency, comparable to - yet also deeply different to - the representative or fiat currency the Western economists later imagined operated on Yap. Or perhaps into something else entirely.

\section{Conclusion}

Existing comparisons between stone money and Bitcoin appear untenable, misleading, and contribute to a long history of colonial appropriation and misrepresentation of Yapese economic cultures. However, I suggest that Yapese economic cultures ought to continue to be represented in economics textbooks, if only to start to transform the debt incurred in previous misrepresentations. There is an opportunity to correct at least the most striking factual errors, and to introduce economics students to salient concepts in economic anthropology, as well as food for thought about the intersection between colonial histories the history and nature of money.

\section{Works Cited}

Amacher, Ryan C. 1983. Principles of Economics. 2nd ed. Cincinnati: South-Western Pub. Co.

Ammous, Saifedean. 2018. The Bitcoin Standard: The Decentralized Alternative to Central

${ }^{30}$ Cf. Throop (2010), p. 21. 
Banking. Hoboken, New Jersey: Wiley.

Angell, Norman. 1929. The Story of Money. Garden City, N.Y.: Garden City Pub. Co., Inc.

Baumol, William J., and Alan S. Blinder. 1985. Economics: Principles and Policy. 3rd ed. San Diego: Harcourt Brace Jovanovich.

Baumol, William J., Alan S. Blinder, and John L. Solow. 2020. Macroeconomics: Principles and Policy. 14th ed. Boston, MA: Cengage Learning.

Beauclair, Inez de. 1963. 'The Stone Money of Yap'. Bulletin of the Institute of Ethnology, no. $16: 147-60$.

Descantes, Christophe. 2005. Integrating Archaeology and Ethnohistory: The Development of Exchange between Yap and Ulithi, Western Caroline Islands. BAR International Series 1344. Oxford: Archaeopress.

Dodd, Nigel. 2018. 'The Social Life of Bitcoin'. Theory, Culture \& Society 35 (3): 35-56. https://doi.org/10.1177/0263276417746464.

Egan, James. 1998. Taro, Fish, and Funerals: Transformations in the Yapese Cultural. $\mathrm{PhD}$ thesis. University of California, Irvine.

Fitzpatrick, Scott M. 2003. 'Stones of the Butterfly: An Archaeological Investigation of Yapese Stone Money Quarries in Palau, Western Micronesia.' PhD thesis, University of Oregon.

Fitzpatrick, Scott M., and Stephen McKeon. 2020. 'Banking on Stone Money: Ancient Antecedents to Bitcoin'. Economic Anthropology 7 (1): 7-21. https://doi.org/10.1002/sea2.12154.

Frank, Robert H., and Ben Bernanke. 2001. Principles of Economics. Boston, Mass: McGraw-Hill/Irwin.

Frank, Robert H., Ben Bernanke, Kate L. Antonovics, and Ori Heffetz. 2019. Principles of Economics. Seventh edition. The McGraw-Hill Series in Economics. New York, NY: McGraw Hill Education.

Furneaux, Nick. 2018. Investigating Cryptocurrencies: Understanding, Extracting, and Analyzing Blockchain Evidence. Indianapolis, IN: Wiley.

Furness, William Henry. 1910. Island of Stone Money: Uap of the Carolines. Philadelphia \& London: J.B. Lippincott Company.

Gibson-Graham, J. K. 2007. A Postcapitalist Politics. Minneapolis: University of Minnesota Press.

Gillilland, Cora Lee C. 1975. The Stone Money of Yap: A Numismatic Survey. City of Washington: Smithsonian Institution Press.

Glumac, Bosiljka, and Scott M. Fitzpatrick. 2020. 'Yapese Stone Money: Local Marble as a Potential Inspiration for Producing Limestone Exchange Valuables in Palau, Micronesia'. In Cultures of Stone: An Interdisciplinary Approach to the Materiality 
of Stone.

Graeber, David. 2011. Debt: The First 5,000 Years. Brooklyn, N.Y: Melville House.

Hage, Per, and Frank Harary. 2010. Island Networks Communication, Kinship, and Classification Structures in Oceania. Cambridge; New York: Cambridge University Press.

Haskin, Byron. 1954. His Majesty O'Keefe. Norma Productions. https://www.imdb.com/title/tt0045876/.

Humphrey, Caroline. 1985. 'Barter and Economic Disintegration'. Man 20 (1): 48. https://doi.org/10.2307/2802221.

Hunter-Anderson, Rosalind, and Yigal (Go'ospan) Zan. 1996. 'Demystifying the Sawei, A Traditional Interisland Exchange System'. Isla: A Journal of Micronesian Studies 4 (1): $1-45$.

Jevons, William Stanley. 1875. Money and the Mechanism of Exchange. New York: D. Appleton and Company.

Klingman, Lawrence, and Gerald Green. 1950. 'His Majesty O’Keefe'. New York: Scribner.

Krause, Stefan M. 2015. 'The Art of Communication in Yap, FSM: Traditional Forms of Respectful Interactions'. In Traditional Knowledge and Wisdom: Themes from the Pacific Islands. ICHCAP.

Labby, David. 1976. The Demystification of Yap: Dialectics of Culture on a Micronesian Island. Chicago: University of Chicago Press.

Lessa, William A. 1950. 'The Place of Ulithi in the Yap Empire'. Human Organization 9 (3): 16-18.

Lingenfelter, Sherwood G. 1972. Political Leadership and Culture Change in Yap. PhD thesis, University of Pittsburgh.

Mankiw, N. Gregory. 2019. Macroeconomics. 10th ed. New York, NY: Worth Publishers / Macmillan Learning.

Martin, Felix. 2014. Money: The Unauthorized Biography. London: Vintage.

Miles, David D, and Andrew Scott. 2002. Macroeconomics: Understanding the Wealth of Nations. 1st ed.

Moore, W. Robert. 1952. 'Grass-Skirted Yap'. National Geographic, 1952.

Müller, Wilhelm. 1918. Yap. Vol. 2. 2 vols. Ergebnisse Der Südsee-Expedition 1908-1910. Hamburg: L. Friederichsen \& Co.

Pine, Art. 1984. 'Fixed Assets, Or: Why a Loan in Yap Is Hard to Roll Over --- Tiny Micronesian Island Uses Giant Stones as Currency; Don't Forget Your Change'. Wall Street Journal, Eastern Edition, 29 March 1984. 
Rospabé, Philippe. 1995. La Dette de Vie: Aux Origines de La Monnaie Sauvage.

Collection 'Recherches'. Série 'Bibliothèque Du M.A.U.S.S.' Paris: Découverte : M.A.U.S.S.

Ruffin, Roy, and Paul R. Gregory. 1997. Principles of Macroeconomics. 6th ed. The Addison-Wesley Series in Economics. Reading, Mass: Addison-Wesley.

Stephenson, Neal. 1995. 'The Great Simoleon Caper'. TIME, 1995.

Takhteyev, Yuri, and Mariana Mota Prado. 2014. 'Bitcoin Goes Boom', 31 January 2014. https://www.foreignaffairs.com/articles/2014-01-30/bitcoin-goes-boom.

Williamson, Stephen D. 2005. Macroeconomics. 2nd ed. The Addison-Wesley Series in Economics. Boston: Addison-Wesley. 